\title{
THERMO-ECONOMIC ANALYSIS OF A HEAT RECOVERY STEAM GENERATOR COMBINED CYCLE
}

\author{
O. O. Ighodaro ${ }^{1, *}$ and M. Osikhuemhe \\ 1,2, Department of MeChanical Engineering, University of Benin, Benin City, Edo STATE. NIGERIA \\ E-mail addresses: ${ }^{1}$ osarobo.ighodaro@uniben.edu, ${ }^{2}$ martino4real2001@yahoo.com
}

\begin{abstract}
A significant amount of energy gets lost through the exhaust of simple gas turbine plants, more often than not, this energy can be used to run another power cycle or a combined heat and power setup, leading to an increase in the overall efficiency of the plant, reduce air pollution and energy wastage. In this study, a retrofitted performance analysis of incorporating a steam power cycle to the existing gas turbine cycle in Delta IV power station is carried out, the analysis is carried out using first law of thermodynamics and energy cost comparison to describe the effect of combining both cycles on power output, thermal efficiency and energy cost. Operating data were obtained from existing gas thermal plant in Ughelli (Delta IV) and steam thermal plant in Lagos (Egbin). Preliminary assessment shows that power output increases by a further 51.5MW, thus raising the overall combined efficiency to $41.85 \%$. Analysis on cost savings accruable from incorporating a heat recovery steam generation was also done and significant savings in cost was obtained.
\end{abstract}

Keywords: combined cycle, HSRG, gas turbine, steam turbine, energy cost,

\section{INTRODUCTION}

The worlds increasing population and rapid industrialization requires sustainable energy supply which is crucial for development. Climate concerns requires that clean, climate friendly and affordable energy technologies be deployed in harnessing it [1]. Growing concerns and challenges in the fossil fuel industry and due to recent advancements in energy sustainable systems, the combined cycle arrangement is attracting lots of research interest, as it is regarded as the most efficient energy conversion system in addition to significantly reducing emissions and energy wastage [2].

The combined cycle power plant is the arrangement of a gas turbine with a steam bottoming cycle, the basic principle entails powering the gas turbine by burning gas fuel by a coupled generator, the high temperature exhaust gas is recovered in a heat recovery steam generator (HRSG) which is then used to produce steam for the steam power cycle, which then produces additional power. Combined cycle plants are known to be more efficient than conventional single generating plants with efficiencies as high as $60 \%$ in some cases [3]

The installation of heat recovery steam generator (HRSG) and steam power plant equipment to achieve a combined cycle configuration is a more attractive option since it does not require modification of the existing gas turbine and the construction of the steam power plant will not interfere with the operation of the turbine resulting in minimum plant downtime and loss in productive capacity.

A number of authors have researched on combined cycle arrangement and performance improvement options. Khan, et al [4] carried out thermodynamic analysis to investigate new advancements of high performance for combined cycle power plants, their study used parametric analysis to optimize the performance of the combined cycle arrangement which included a bypass valve, the result obtained showed a $45 \%$ gain in power output when the inlet temperature of the topping cycle increases from $1000 \mathrm{~K}$ to $1400 \mathrm{~K}$, Lacopo, et al [4] also used thermodynamic analysis to investigate the most 
efficient match for a vapour cycle bottoming cycle using the $2^{\text {nd }}$ law of thermodynamics, results showed a $12 \%$ increase in efficiency of the vapour cycle. Bianchi, et al [5] and Zhu, et al [6] studied the possibility of using the waste heat from gas turbine plants to power a bottoming cycle, Macian, et al [7] went on to develop optimization options of bottoming cycle which can then be used in waste heat recovery systems in vehicles. Polyzakis, et al [8] carried out optimization of combined cycle reheat arrangement, results indicating that the reheated gas turbines are the most viable option. Xiang, et al [9] studied performance improvement and optimization of selected combined cycle power plants in china, the results obtained from the study shows that increasing the HRSG inlet temperature beyond $590^{\circ} \mathrm{C}$ does not significantly improve cycle efficiency and with HRSG optimization with the use of gas to gas heat recuperation increases the combined cycle efficiency to $59 \%$.

The gas turbine exhaust, typically at a temperature of $500-600^{\circ} \mathrm{C}[10]$ is used to raise steam in the HRSG; this steam is then used in steam turbine to drive a generator. The turbine exhaust has unused oxygen content and it is possible to burn additional fuel in the boiler to raise steam output; this supplementary firing is most used with gas turbine operating at a relatively low exhaust gas temperature [11]. The exhaust from the HRSG may be used in processes such as paper drying, brewing, heating of building, sterilizing or for preheating combustion air for the furnace at a carbon baking facility, this is referred to as Cogeneration or combined Heat and Power (CHP). Zhang, et al [12] and Peris, et a/[13] carried out studies on utilizing the waste heat from internal combustion engines, both papers show that power output improved marginally when heat recovery was incorporated.

\section{SYSTEM DESCRIPTION}

The combined cycle arrangement is the combination of two cycle with the primary aim of improving work output and overall efficiency, the primary cycle, termed the topping cycle is the gas power cycle working on the principle of the Brayton cycle, its highquality exhaust heat is used to run the second cycle, termed the bottoming cycle which in this case is the steam power cycle working on the principle of the Rankine cycle. The working fluid of the topping cycle is combustible gases while that of the bottoming cycle is steam. The gas turbine plant to be used for this analysis is the Delta IV Power Station, Ughelli while the steam power plant used is the Egbin Power Station, Ikorodu.

In the gas turbine (topping) cycle, air at atmospheric pressure and temperature $\left(p_{5}, T_{5}\right)$ enters the compressor, where it is compressed to higher pressure and temperature $\left(p_{6}, T_{6}\right)$. This high pressure and temperature air enter the combustion chamber where fuel gas is added in the combustion process. After leaving the combustion chamber, the products of combustion at pressure and temperature $\left(p_{6}, T_{7}\right)$ enters the turbine where it expands to the temperature $T_{8}$. On leaving the turbine, the quality of the exhaust gases is still significantly high as well as the amount of energy in the gasses. Such gases if allowed to exhaust in to the environment (as currently the case in Delta IV), they will contribute to global warming.

In order to extract this energy and save the plant, a heat recovery steam generator (HRSG) is installed in the exhaust channel, after which the gases exhaust to the atmosphere at temperature $T_{9}$. The HRSG acts as the combustion chamber for the bottoming cycle.

In the bottoming (steam power) cycle, condensed feed water enters the pump at state $1\left(p_{1}\right)$ where it is pumped to higher pressure and temperature $\left(p_{2}, T_{2}\right)$ before entering the HRSG where superheated steam is generated at $\left(p_{3}, T_{3}\right)$, before entering the turbine where it is expanded to the condenser conditions of p4. Figure 1 shows the schematic of the proposed combined cycle arrangement and its corresponding T$s$ diagram.

Although the characteristics compactness of the gas turbine is sacrificed in binary cycle plants the efficiency is much higher than is obtainable with the simple cycle such that turbines are now widely used for large scale electricity generating stations [14]

\subsection{Thermodynamic analysis of Gas Power Cycle (Delta IV)}

In the gas turbine topping cycle, data used in computing the work output and thermal efficiency were obtained from the research work on Delta IV power station by Ighodaro [10]. Using the states in Figure 1, the turbine work $\left(\mathrm{W}_{\mathrm{tg}}\right)$ in the gas power cycle is given by:

where

$$
W_{t g}=m_{g} c_{p g}\left(T_{7}-T_{8}\right)
$$

$$
T_{8}=T_{7}\left\{1-\eta_{t}\left(1-r_{p}^{-\beta}\right)\right\}
$$




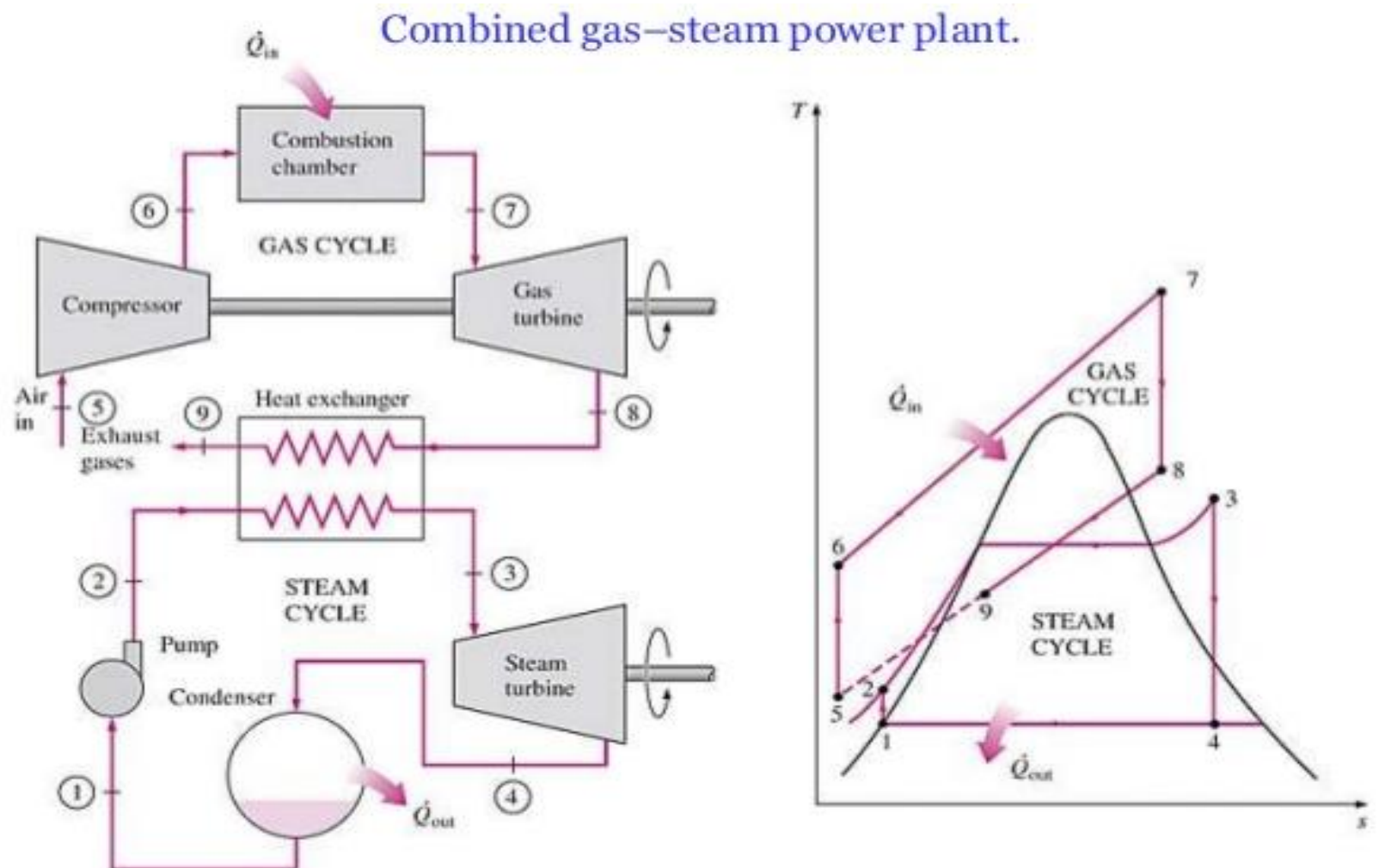

Figure 1: Schematic Diagram of Combined Gas \& Steam Power Cycle

The compressor work $\left(\mathrm{W}_{\mathrm{cg}}\right)$ in the gas power cycle is given by:

$$
W_{c g}=m_{a} c_{p a}\left(T_{6}-T_{5}\right)
$$

where

$$
T_{6}=T_{5}\left\{1+\frac{\left(r_{p}^{-\alpha}-1\right)}{\eta_{c}}\right\}
$$

The network output of the gas power plant $\left(\mathrm{W}_{\text {netg }}\right)$ is given by:

$$
W_{\text {netg }}=W_{t g}-W_{c g}
$$

The heat supplied $\left(Q_{g}\right)$ in the combustion chamber of the gas turbine is given by:

$$
Q_{g}=m_{g} c_{p g} T_{7}-m_{a} c_{p a} T_{6}
$$

The energy efficiency of the gas turbine cycle is given by:

$$
\eta_{g c}=\frac{W_{\text {netg }}}{Q_{g}}
$$

\subsection{Thermodynamic analysis of the HRSG}

A single pressure HRSG is installed to replace the boiler in the steam power plant. The HRSG is expected to reduce the exhaust gas temperature of the gas power cycle before it exhausts to the atmosphere while generating superheated steam for the steam power plant operation.

The heat recovered from the exhaust gases $\left(Q_{r}\right)$ is given by:

$$
Q_{r}=m_{e x} c_{p e x}\left(T_{8}-T_{9}\right)
$$

The portion of the recovered heat transferred in the HRSG which is used to generate steam is given by:

$$
Q_{s}=\varepsilon Q_{r}
$$

\subsection{Thermodynamic analysis of Steam Power Cycle (Egbin)}

In the steam turbine bottoming cycle, data used in computing the work output and thermal efficiency were obtained from the research work on Egbin power station by Ohenhen [15]. Using the states in Figure 1, the turbine work $\left(\mathrm{W}_{\mathrm{ts}}\right)$ in the steam power cycle is given by:

$$
W_{t s}=m_{s}\left(h_{3}-h_{4}\right)
$$

The pump work $\left(\mathrm{W}_{\mathrm{ps}}\right)$ in the steam power cycle is given by:

$$
W_{p s}=v_{f}\left(p_{2}-p_{1}\right)
$$

The network output of the steam power plant ( $\left.W_{\text {nets }}\right)$ is given by:

$$
W_{\text {nets }}=W_{t s}-W_{p s}
$$

The energy efficiency of the steam turbine cycle is given by:

$$
\eta_{s c}=\frac{W_{\text {nets }}}{Q_{s} \eta_{\text {mech }} \eta_{\text {gen }}}
$$




\subsection{Thermodynamic analysis of retrofitted combined cycle}

The combined cycle is the combination of the gas turbine (topping) and steam turbine (bottoming) cycles as shown in Figure 1. The combination increases the network output of the cycle and the efficiency.

The network of the combined cycle ( $\left.W_{\text {netcc }}\right)$ is given by:

$$
W_{\text {netcc }}=W_{\text {netg }}+W_{\text {nets }}
$$

The overall efficiency of the combined cycle is given by:

$$
\eta_{o c}=\frac{W_{n e t c c}}{Q_{g}}
$$

\section{ENERGY COST ANALYSIS}

The fuel or energy costs, $E_{c}$ (mills/kWh) for natural gas fired power station is given by [14]:

$$
E_{c}=\frac{F_{c}\left(\frac{\text { dollar }}{k W h}\right) \times 100\left(\frac{\text { mills }}{\text { dollars }}\right)}{\eta_{o c} Q_{\text {net }}\left(\frac{k J}{k W h}\right) \times k W h / 3600 \mathrm{~kJ}}=\frac{3.6 \times 10^{6} F_{c}}{\eta_{o c} Q_{\text {net }}}
$$

Where: $F_{c}=$ Fuel cost in Dollars $/ \mathrm{kWh} ; Q_{\text {net }}=$ energy release per unit fuel mass, $\mathrm{kJ} / \mathrm{kWh} ; \eta_{o c}=$ overall thermal efficiency; Mills $/ \mathrm{kWh}=$ standard expression for cost of electricity (1mill/kWh $=\$ 1 / \mathrm{MWh}$ $=$ N360/MWh)

Exchange rate as at July 2006: $\$ 1=\mathrm{N} 150$ (the period for which Power Station operation data is available)

\section{RESULTS AND DISCUSSION}

The network output of the power stations when operating individually and when combined in a combined cycle set up is shown in Figure 2.

The Thermal efficiencies of the power stations when operating individually and when combined in a combined cycle set up is shown in Figure 3.

As seen from Figure 2, the installation of a combined cycle arrangement instead of the existing individual gas and steam power plants creates a considerable increase in power output from the individual 89.9MW and $53.6 \mathrm{MW}$ for the gas and steam plants respectively to the $143.5 \mathrm{MW}$ for the combined cycle, also from Figure 3 the same appreciable gain in thermal efficiency is noticed from the $24.4 \%$ for the gas turbine cycle to the $37.9 \%$ for the combined cycle power plant.

A further comparison of Figure 2 and 3, shows that although the power output of the steam cycle is less than that of the gas cycle, the efficiency of the steam is much higher than that of the gas, this is due to the far less heat supplied in the steam cycle due to the presence of air preheaters and economizers in the boiler pathway in the steam turbine.

The considerable gain in power output and thermal efficiency noticed in Figures 2 and 3 makes the combined cycle plant suitable for base load power generation due to reduced cost of generation. To avoid having one steam turbine train for each gas turbine unit, it is more economical to have two gas turbines and HRSG to drive one steam turbine train as used in the design of the AGIP power installation in Kwale, Delta State. In such instance, the power output from the steam power output from the steam turbine generator terminal would be greatly increased.

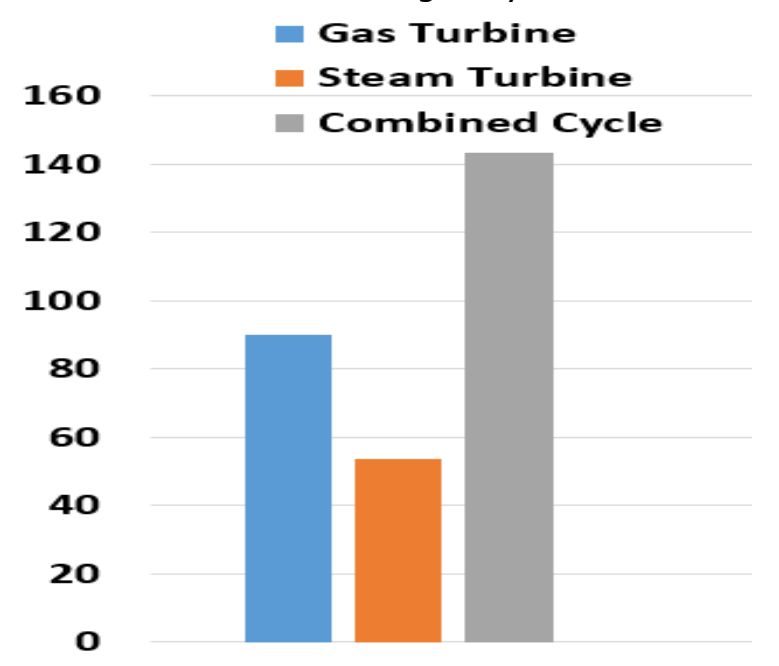

Figure 2: Network output of Power Stations

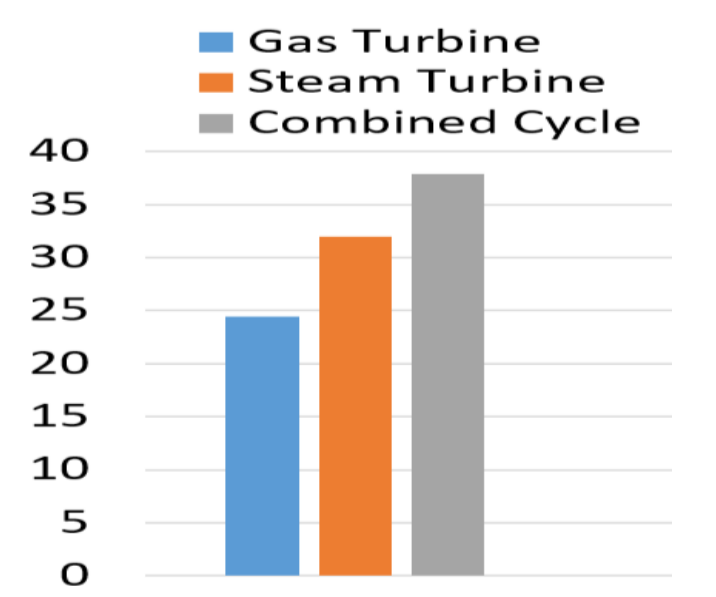

Figure 3: Thermal Efficiencies of Power Stations

\subsection{Energy cost analysis for gas turbine plant when used as base load carrier}

Using GT 15 as a case study for the period from January 2004-March 2005:

Total energy generated $=907,504 \mathrm{MWh}$

Overall thermal efficiency at full load $=24.6 \%$

Fuel cost $=$ N65/mc $*$ 
Amount of fuel supplied $=11,872,952 \mathrm{mcf}$

Cost of unit of fuel in Naira $=$ N0.2159/kWh

Net energy release per unit of fuel:

$$
1030 \frac{B t u}{c f} \times 1.054 \times \frac{10^{3}}{B t u} \times \frac{k J}{1000 J}=1085.6 \mathrm{~kJ} / \mathrm{cf}=
$$

$3.61 \times 10^{3} \mathrm{~kJ} / \mathrm{kWh}$

Using Equation 16:

$$
\begin{aligned}
E_{c}=\frac{3.6 \times 10^{6} \mathrm{Fc}}{\eta_{o} Q_{\text {net }}} & =\frac{3.6 \times 10^{6} \times 0.2159}{0.244 \times 3.61 \times 10^{3}} \\
= & 882.4 \mathrm{mills} / \mathrm{kWh}
\end{aligned}
$$

Total cost of fuel for GT $15=\mathrm{N} 882.4 \times 907504=$ N800.8 Million

Assume all five GTs are working as Gt 15 , total energy generated by station;907 $504 \times 6=5445024 \mathrm{MWh}$

Total cost of fuel for GTs in station: $882.4 \times 5445024$

$=\mathrm{N} 4.8$ billion

\subsection{Energy cost analysis when gas turbine plant is incorporated in the combined cycle arrangement}

Total energy generated $=1308752 \mathrm{MWh}$

Overall thermal efficiency at full load $=37.4 \%$

Fuel cost $=\mathrm{N} 65 / \mathrm{mcf}$

Amount of fuel supplied $=11872.952 \mathrm{mcf}$

Cost of unit of fuel $=\mathrm{N} 0.2159 / \mathrm{kWh}$

Net energy released per unit fuel

\section{$3.61 \times 10^{3} \mathrm{~kJ} / \mathrm{kWh}$}

$$
1030 \frac{B t u}{c f} \times 1.054 \times \frac{10^{3}}{B t u} \times \frac{k J}{1000 J}=1085.6 \mathrm{~kJ} / \mathrm{cf}=
$$

Using the earlier developed equation:

$\mathrm{E}_{\mathrm{c}}=\frac{3.6 \times 10^{6} \mathrm{Fc}}{\eta_{o} Q_{\text {net }}}=\frac{3.6 \times 10^{6} \times 0.2159}{0.374 \times 3.61 \times 10^{3}}=575.7 \mathrm{mills} / \mathrm{kWh}$

Total cost of fuel for GT $15=$ N575.7 $\times 1308725=$ N735.4 million

Assume all five GTs are working as GT 15, total energy generated by station:

$1308725 \times 6=7852350 \mathrm{MWh}$

Total cost of fuel for GTs in station: $575.7 \times 7852350$

$=\mathrm{N} 4.52$ billion

\subsection{Saving in Fuel Cost by Using A Combined Cycle}

Saving in cost of fuel per GT $=$ N800.8 million N735.3million $=$ N47.5million

Savings in cost of fuel for station $=\mathrm{N} 4.8$ billion $-\mathrm{N} 4.52$ billion $=$ N280 million

As seen from the above hypothetical combined cycle scheme a considerable increase in power output production is achieved at a much higher efficiency, the use of supplementary firing would increase cost of fueling but gives much higher output from the steam

turbine generator terminal, then the advantage of a further increase in output to be gained from combined cycle arrangement would have to be weighed against the increased cost of fueling.

\section{CONCLUSION}

A thermodynamic analysis for incorporating a steam turbine plant and a gas turbine plant in a combined cycle arrangement using a heat recovery steam generator has been explored and a performance evaluation and cost analysis has been efficiently applied. The results improve the understanding of such combined cycle behaviors, revealing that the combined cycle plant provides a much higher load output, significant improvement in efficiency, and even though there is a greater complexity in the plant and a higher cost of equipment, there is considerable reduction in the fuel cost.

The possibility of incorporating a steam turbine unit to utilize the high exhaust gas from the gas turbine unit (combined cycle) was studied: the findings reveal a much higher load output, improved efficiency and reduced fuel cost.

Table 1: Major Assumptions and Conversion Units.

\begin{tabular}{ll}
\hline Assumptions and Conversion units \\
\hline Isentropic efficiency of gas and & 90 \\
steam turbine & 99 \\
Mechanical efficiency & 97 \\
Generator efficiency & $298 \mathrm{~K}$ \\
Ambient Temperature & 0.9 \\
Heat exchanger effectiveness & $420 \mathrm{Kg} / \mathrm{s}$ \\
Mass flow rate of air in gas turbine & \\
cycle & $22 \mathrm{Kg} / \mathrm{s}$ \\
Mass flow rate of fuel in gas turbine & \\
cycle & $630 \mathrm{~kg} / \mathrm{s}$ \\
Mass flow rate of feed water in & $1.14 \mathrm{~kJ} / \mathrm{kg}$ \\
steam turbine cycle & $\mathrm{K}$ \\
Specific heat of gas & 1.005 \\
& $\mathrm{~kJ} / \mathrm{kg} \mathrm{K}$ \\
specific heat of air & 1.14 \\
Ratio of specific heat for air & 1.33 \\
Ratio of specific heat for gases & $443 \mathrm{~K}$ \\
Temperature of exhaust gases from & $\mathrm{N} 0.22 / \mathrm{kW}$ \\
HRSG & $\mathrm{h}$ \\
Unit cost of Natural gas & $\mathrm{N} 130 / 1 \$$ \\
Dollars conversion rate & $1 \mathrm{mcf}=301$ \\
Energy conversion rate & $\mathrm{kWh}$
\end{tabular}




\section{REFERENCES}

[1] Khan M.N, Tlili I; New Advancement of High Performance for a Combined Cycle Power Plant: Thermodynamic Analysis, Case Studies in Thermal Engineering 12, 2018 pp 166-175.

[2] Ehsan Noorollahi, Dawud Fadai, Seved Hassan Ghodsipour, Mohsen Akbarpur Shirazi; A new optimization framework for power generation expansion planning with the inclusion of renewable energy-a case study of Iran, J. Renew. Sustain. Energy, 9, 2017, pp 15-30.

[3] Alessandro Franco, Claudio Casarosa; On some perspective for increasing the efficiency of combined cycle power plants, Applied Thermal Engineering 22(13), 2002, pp 1501-1518.

[4] Lacopo Vaja, Agostino Gambaro; Internal combustion engine (ICE) bottoming with organic rankine cycle (ORCs), Energy 35, 2010, pp 10841093.

[5] M. Bianchi, A De Pascale; Bottoming cycles for electric energy generation parametric investigation of available and innovative solutions for the exploitation of low and medium temperature heat sources, Appl. Energy, 88, 2011, pp 1500-1509.

[6] Sipeng Zhu, Kangyao Deng, Shuan Qu; Energy and exergy analysis of a bottoming rankine cycle for engine exhaust heat recovery, Energy, 58, 2013, pp 448-457.

[7] V. Macian, J.R Serrano, V. Dolz, J. Sanchez; Methodology to design a bottoming Rankine cycle, as a waste energy recovering system in vehicles. Study in a HDD engine. Appl. Energy, 104, 2013, pp 758-771.

[8] A.L Polyzakis, C. Koroneos, G. Xydis; Optimum gas turbine cycle for combined cycle power plant, Energy Convers. Manag., 49, 2008, pp. 551-563.
[9] Wenguo Xiang, Yingying Chen; Performance improvement of combined cycle power plant based on the optimization of the bottom cycle and heat recuperation, J. Therm. Sci., 16 (1), 2007, pp 84-89.

[10] Ighodaro O. O.; Performance Appraisal of Delta IV Power Station Ughelli, M.Eng Thesis. Thermal Power Engineering, University of Benin, 2006.

[11] I. H. Njoku, C.O.C Oko, J.C. Ofodu; Performance evaluation of a combined cycle power plant integrated with organic Rankine cycle and absorption refrigeration system; J. of Cogent Engineering 5, 2018, 1451426

[12] H.G Zhang, E.H. Wang, B.Y. Fan; A performance analysis of a novel system of a dual loop bottoming organic Rankine cycle (ORC) with a light-duty diesel engine, Appl. Energy, 102, 2013, pp 504-1513.

[13] Bernardo Peris, Joaquin Navarro-Esbri, Francisco Moles; Bottoming organic Rankine cycle configurations to increase internal combustion engine power output from cooling water waste heat recovery, Appl. Therm. Eng., 61, 2013, pp. 364-371.

[14] Weismann J and Eckert R; Modern Power Plant, Textbook, 1995, UK: Prentice Hall.

[15] Ohenhen A. G.: Turbine Inspection and Testing (A case Study Of Lagos Thermal Power Station Egbin, Lagos) (M.Eng Project), University Of Benin, 1998.

[16] Attah S. P. : Performance Appraisal of Power Generation At the Aluminum Smelter Company, Ikot Abasi (M.Eng Project), University of Benin, 2001. 